\title{
Erratum to: The Fixed-Dose Combination of Olmesartan/Amlodipine Was Superior in Central Aortic Blood Pressure Reduction Compared with Perindopril/Amlodipine: A Randomized, Double-Blind Trial in Patients with Hypertension
}

Luis Ruilope $\cdot$ Angie Schaefer

To view enhanced content go to www.advancesintherapy.com

Published online: February 25, 2015

(c) The Author(s) 2015. This article is published with open access at Springerlink.com

Erratum to: Adv Ther (2013) 30(12):1086-1099

DOI: $10.1007 / \mathrm{s} 12325-013-0076-6$

Some errors have been noted in the abovementioned paper subsequent to publication and so the following corrections should be highlighted.

On page 1091 under the heading Treatment Patterns, the sentence "Overall, the mean duration of treatment was 152.6 days, and there were no major differences between the two treatment groups, including the duration of

The online version of the original article can be found under doi:10.1007/s12325-013-0076-6.

L. Ruilope $(\bowtie)$

Hypertension Unit, Hospital 12 de Octubre,

28041 Madrid, Spain

e-mail: ruilope@ad-hocbox.com

L. Ruilope

Department of Preventive Medicine and Public

Health, Universidad Autonoma, Madrid, Spain

A. Schaefer

Daiichi Sankyo Europe GmbH, Zielstattstrasse 48,

81379 Munich, Germany add-on HCTZ treatment" should read "Overall, the mean duration of treatment was 151.2 days, and there were no major differences between the two treatment groups, including the duration of add-on HCTZ treatment." It should be clarified that 152.6 days was the mean duration of the double-blind treatment phase.

On page 1092 in Fig. 3, the $p$ value for the FAS group should read $p=0.0005$, and not $p<0.0001$.

On page 1095 under the heading Safety/ Tolerability, the sentence "The most common adverse event was peripheral edema, which was reported in $17.8 \%$ of OLM/AML patients and $18.1 \%$ of PER/AML recipients" should read "The most common adverse event was peripheral edema, which was reported in $18.4 \%$ of OLM/ AML patients and $17.8 \%$ of PER/AML recipients."

On page 1095 in Table 2, the values in the row showing the frequencies of peripheral edema which are currently: 43 (17.8) in the OLM/AML column, 88 (18.1) in the PER/AML column, and 45 (18.4) in the total column; should read: 45 (18.4), 43 (17.8), and 88 (18.1), respectively. 
Open Access. This article is distributed under the terms of the Creative Commons Attribution License which permits any use, distribution, and reproduction in any medium, provided the original author(s) and the source are credited. 